\title{
INFORMALIDADE EM GOIÂNIA: UMA ANÁLISE SOBRE O MERCADO ABERTO ${ }^{1}$
}

\author{
OLIVEIRA, Geruza Silva ${ }^{2}$
}

RESUMO: A proposta deste é discutir a intervenção, num espaço público em Goiânia, por meio de um projeto idealizado e desenvolvido na Avenida Paranaíba (Centro), desta cidade, que recebeu a denominação de Mercado Aberto. Para tanto, estudar-se-á neste ponto a concepção do mercado, bem como seu traçado, seu funcionamento e normatizações, os tributos concedidos ao mesmo tempo pelo vendedor-feirante e pelo consumidor, tomando-o (o Mercado Aberto) como um espaço de conflitos, onde as regras são passíveis de ser burladas. Utilizou-se de pesquisa quali-quantitativa realizada por meio de levantamentos efetuados na Secretaria Municipal de Desenvolvimento Econômico (SEDEM) ${ }^{3}$, a técnica da observação participante, questionários com perguntas abertas e entrevistas semi-estruturadas.

Palavras-Chave: mercado, espaço, conflito.

\section{INTRODUÇÃO}

\section{Mercado Aberto: sua concepção.}

Ao definir as Diretrizes de Desenvolvimento para o Município e a Política Urbana, o PIDG (2000) aprovou o Plano Diretor, instituiu os Sistemas de Planejamento Territorial Urbano e de Informações Territoriais do Município e deu outras providências. As Diretrizes de Desenvolvimento para o Município, propostas no artigo $1^{\circ}$ da Lei $^{4}$, referiam-se ao meio para a promoção de seu desenvolvimento sustentado, como vetor da condição desejável a ser alcançada no ordenamento do território, objeto da política urbana. Entre as várias diretrizes apresentadas, devem ser mencionadas as de Política Urbana do Município de Goiânia, entre as quais a proposta para o Setor FísicoTerritorial-Ambiental e Cultural de promover o redisciplinamento do solo usado, através da adequada distribuição da população, das atividades econômicas e dos equipamentos públicos e comunitários, compatibilizando as condições físicas e bióticas do território com a reorientação para o crescimento ordenado da cidade.

De acordo com o artigo $3^{\circ}$ da Lei Complementar, a política urbana do município de Goiânia tem por objetivo prover o ordenamento territorial, visando ao pleno desenvolvimento das funções sociais da cidade e da propriedade urbana e rural, em consonância com as diretrizes de desenvolvimento para o município. O objetivo principal dessa política é garantir o bem-estar de seus habitantes, devendo ser implementada em parceria com a iniciativa privada, através da implantação do Plano Diretor, instrumento básico dessa política, e dos demais instrumentos e institutos jurídicos complementares.

Essa política desenvolve-se com o auxílio de diretrizes de desenvolvimento para o município, em consonância com a ordenação territorial e a política urbana,

\footnotetext{
${ }^{1}$ Texto em formato de artigo apresentado à Revista Eletrônica da Faculdade de Ceres. Resultados parciais da Dissertação de Mestrado defendida e aprovado em 2005, na Faculdade de Ciências Sociais na Universidade Federal de Goiás.

${ }^{2}$ Mestre em Sociologia. Doutoranda em Sociologia. Professora da FACER e FACERES. Coordenadora da CPA na FACER e FACERES.

${ }^{3}$ SEDEM - Órgão integrante da estrutura administrativa da Prefeitura de Goiânia, o qual tem por finalidade promover a execução da Política Municipal de Desenvolvimento Econômico da cidade.

${ }^{4}$ Lei complementar n. ${ }^{\circ} 015$, de 30 de dezembro de 1992, publicada no Diário Oficial do Município de Goiânia n. ${ }^{\circ} 1.1019$ em 1 de fevereiro de 1993.
} 
categorias que englobam as diretrizes gerais e setoriais. As primeiras diretrizes, contidas no art. $5^{\circ}$, referem-se à promoção do crescimento, prefencialmente a sudoeste do município, à ordenação e controle do uso do solo e à transação urbana, evitando-se a sub-utilização dos investimentos públicos.

De acordo com o artigo $7^{\circ}$ da Lei, o Plano Diretor de Goiânia é o instrumento básico da Política Urbana e de orientação dos agentes públicos e privados que atuam na produção e gestão da cidade. $\mathrm{O}$ artigo $8^{\circ}$ define, como seus objetivos, os de compatibilizar a ordenação do território municipal com o desenvolvimento econômico social, bem como a proteção do patrimônio cultural e ambiental; ordenar o crescimento da cidade, observando-se as diretrizes da Lei Orgânica do Município; vincular a atuação da administração municipal à política urbana do município; propiciar condições para a programação dos equipamentos urbanos e dos serviços municipais com vistas ao desempenho das atividades econômicas e às demandas sociais; fixar os critérios que assegurem a função social da propriedade, observando o disposto no parágrafo $1^{\circ}$, do artigo 157 da Lei Orgânica do Município.

Goiânia sofreu intervenções em seus espaços urbanos advindos dos planos de ações governamentais ao longo de sua história, assim como do Plano Diretor vigente. Um exemplo é o espaço da Avenida Goiás, denominada de Avenida Dr. Pedro Ludovico Teixeira, em homenagem ao governador do Estado na década de 1930. Em dezembro de 1935, pelo Decreto . $^{\circ}$ 657, o governador mudou o nome da avenida para Avenida Goiás, dando a ela grande importância histórica na cidade, por ser considerada a principal avenida de Goiânia e por trazer o nome da antiga capital de Goiás.

Pertencente à centralidade histórica da cidade, essa avenida foi, ao longo dos anos, transformada pela informalidade, tornando-se palco do mercado ambulante, que a ocupou, e que foi posteriormente transferido para o Mercado Aberto, na Avenida Paranaíba. Nesta avenida, puderam ser verificadas ações de outros grupos sociais que, de alguma forma, deixaram suas marcas, ressignificando o local de acordo com seus desejos, práticas e necessidades: hippies, meninos em situações de risco pessoal (meninos de rua), mendigos e vândalos, além de intervenções do próprio governo ${ }^{5}$ que, de alguma maneira, agiu na materialidade do espaço público e da memória social, desvinculando-se do seu plano.

No contexto da influência da informalidade, a Avenida Goiás, como outros pontos centrais da cidade $^{6}$, inseriu-se no Programa de Revitalização do Centro de Goiânia. ${ }^{7}$ Amparado pelo Plano Diretor no que tange às proteções cultural e ambiental,

\footnotetext{
${ }^{5}$ Vale ressaltar que, nas décadas de 1930 e 1940, a Avenida Goiás foi construída para ser a grande referência da cidade de Goiânia; nas décadas de 1950 e 1960, os canteiros centrais sofreram pequenas alterações mas que, entretanto, não a descaracterizam como Avenida-jardim; na década de 1970, os canteiros ornamentais foram destruídos para a construção do calçadão e na década de 1980 o calçadão foi reduzido quando, então, cerca de 70 árvores foram retiradas da avenida para a implantação das faixas exclusivas para ônibus.

${ }^{6}$ Inseridas no Projeto de Revitalização de Goiânia, estão: (a) a revitalização da Praça Cívica, espaço projetado inicialmente para funcionar como "centro administrativo", de onde partiriam as primeiras avenidas da cidade; (b) a criação do Mercado Aberto, que seria um espaço novo, destinado a abrigar os ambulantes das partes centrais de Goiânia; (c) a requalificação da Avenida Goiás, executada a partir do projeto do arquiteto Jesus Henrique Cheregati; (d) a recuperação de fachadas de prédios da Avenida Goiás; (e) a restauração da Estação Ferroviária, que será transformada em Estação Cultura, por seu prédio ser um dos mais representativos exemplares do estilo adotado na arquitetura inicial, o art déco; (f) a restauração do Grande Hotel; e (g) o alargamento da Avenida Paranaíba. Propostas direcionadas a partir de 2003.

7 São as seguintes as demais obras e ações definidas pelo Grupo de Revitalização do Centro: (a) alargamento da Avenida Paranaíba, entre a Rua 74 e a Avenida Tocantins; (b) implantação das Yellow Boxes, uma sinalização diferenciada, feita no próprio asfalto, em cruzamentos de grande fluxo de
} 
foi, portanto, alvo de mudanças para resgatar a história da cidade. Finalmente, em julho de 2003, foram iniciadas as obras, tendo o Mercado Aberto sido entregue à população em outubro do mesmo ano.

Durante algum tempo, a Avenida Goiás conviveu e dialogou no seu cotidiano com vendedores ambulantes. Estes, ao ocuparem a avenida monumental, assenhorearam-se de um espaço projetado com funções definidas para lazer, de referência turística, como área pública, destinado ao uso de todos que por ali passam, além de constituir monumentalidade, aspecto que, de acordo com a Prefeitura Municipal, deve ser preservado. A esse respeito, Fontanezi (2004) dispõe, que esta avenida, espinha dorsal, eixo de ligação Norte/Sul foi planejada para exercer várias funções: de ligação do espaço central com o todo urbano; de receptora das águas e do esgoto, devido a sua declividade; do escoamento do trânsito em função de sua largura de 50 metros. Socialmente, exerceu a função de espaço de lazer, devido à dimensão e arborização do canteiro central, espaço onde a elite deveria praticar o footing - uma prática que proporcionava o flerte.

Ao oferecer seus produtos à venda nesta via pública, os camelôs - vendedores ambulantes - produzem na cidade um novo uso do mesmo espaço, dotado de características e regras próprias, ultrapassando as limitações do planejamento urbano e criando assim um embate com os projetistas da cidade. Neste processo, tornam-se um problema para as administrações municipais, sendo constantemente associados a degradações estéticas e higiênicas da paisagem urbana, bem como à idéia de malandragem e marginalidade, já que não pagam taxas nem impostos e disputam os potenciais fregueses com o comércio formal. Em razão disto, os órgãos gestores procuram encontrar soluções imediatas para a questão. Essa realidade, construída em moldes de conflitos no espaço público ${ }^{8}$, levou à elaboração e construção do Projeto Mercado Aberto na cidade.

\footnotetext{
veículos e pedestres; (c) recapeamento e implantação de sinalização especial na Marginal Botafogo; (d) remanejamento dos pontos de ônibus do Centro; (e) implantação de estacionamento por parquímetro; (f) implantação de sessenta semáforos com cronômetros para a travessia de pedestres; $(\mathrm{g})$ substituição do asfalto da Avenida Araguaia, entre os parques Mutirama e Botafogo, por concreto intertravado; (h) estudo para elaboração de uma legislação que estabeleça um padrão para as calçadas de Goiânia; (i) projetos para o mobiliário urbano (lixeiras, bancos etc.); (j) implantação de projeto de arborização do Centro; (k) restauração e adequação para instalação de barracas de camelôs na Praça Espírito Santo, ao lado do Parthenon Center; (1) requalificação da Avenida 85; (m) recuperação dos passeios públicos das Avenidas 82 e Universitária, assim como da Rua 26; (n) revitalização do núcleo histórico de Campinas; (o) revitalização e requalificação do Lago das Rosas; (p) revitalização da Praça Tamandaré; (q) reforma de todas as praças da Avenida República do Líbano - Praças do Avião, Piricota e Palestina; (r) revitalização da Praça Universitária; (s) recuperação do Cemitério Santana (conclusão parcial); (t) reforma e transformação do prédio do Indur, em frente ao Teatro Inacabado, em uma casa de artes cênicas, com cursos para a população.

8 A revista Pólis (1996, n.23) traz o exemplo de tratamento radicalizado na gestão do prefeito Jânio Quadros, em São Paulo - 1985 a 1988 -, que cassou licenças e pontos fixos de todos os ambulantes que atuavam no centro da cidade, mesmo dos deficientes físicos, que haviam sido regulamentados durante a administração de Mário Covas. Realizando blitz de surpresa, apoiado em forte esquema policial, o "rapa" (expressão para denominar a fiscalização) recolhia diariamente centenas de barracas de ambulantes que resistiam à expulsão, provocando revoltas e protestos contínuos. No inicio de 1988, a prefeitura criou seis bolsões de Mercadoria Popular ou Camelódromos, como ficaram conhecidos pelo povo, deslocando para esse locais as barracas que estavam montadas no centro, sem comunicação prévia.
} 


\section{MATERIAL E MÉTODOS}

Para apreender a dinâmica da formação do espaço urbano e em um recorte a compreensão da informalidade a partir do Mercado Aberto em Goiânia, utilizou-se de pesquisa quali-quantitativa realizada por meio de levantamentos efetuados na Secretaria Municipal de Desenvolvimento Econômico (SEDEM) ${ }^{9}$, nos quais buscaram-se informações sobre o processo de surgimento e desenvolvimento da informalidade na cidade; sobre os aspectos socioeconômicos dos ambulantes e sobre as transformações apresentadas nos espaços públicos de Goiânia. Outros órgãos também foram consultados, tais como a Secretaria de Planejamento Municipal (SEPLAM), Instituto Brasileiro de Geografia e Estatística (IBGE) e Centro de Documentação do Jornal $O$ Popular (CEDOC).

Como técnica metodológica da pesquisa, utilizou-se, também, da observação participante, vista, por alguns, como originária da antropologia, a partir dos estudos e experiências de campo de Malinowski (DURHAM, 1978, apud HAGUETTE, 2003, p. 66) e, por outros, como tendo sido iniciada pela Escola Sociológica de Chicago, na década de 20, início do século passado (DOUGLAS, 1973, apud HAGUETTE, 2003, p. 66). Utilizou-se também da técnica de entrevistas não estruturadas, cuja referência teórico-metodológica encontra-se na concepção desenvolvida por THIOLLENT (1980), com contribuições de Liliane Kandel, Guy Michelat e Jackes Maître (in: THIOLLENT, idem), ou seja, do processo de entrevista não-diretiva, a qual proporciona maior liberdade ao entrevistado, na exposição de suas idéias, e permite ao pesquisador uma forma metodológica de reter informações para serem, depois, analisadas e interpretadas.

A pesquisa amparou-se, ainda, em recursos mais conhecidos, tais como gravadores e questionários com perguntas abertas. Os questionários tiveram sua aplicação em duas etapas. Na primeira, aplicaram-se sessenta (60) entrevistas, sendo vinte (20) dirigidas a vendedores ambulantes, com atividades informais no Setor Campinas, distribuídos na Praça da Matriz (Santuário Nossa Senhora do Perpétuo Socorro); na Avenida 24 de Outubro; na Rua Jaraguá e Rua José Hermano, com o intuito de se obter uma visão mais globalizada do comércio informal de Goiânia; Vinte (20) questionários foram aplicados aos consumidores do Mercado Aberto. Aplicaramse, ainda, vinte (20) questionários para feirantes do Mercado Aberto.

Estabeleceram-se diálogos informais com fiscais, usuários dos produtos informais ou não, vendedores, feirantes, lojistas do comércio, moradores da cidade e moradores situados ao redor dos espaços ocupados pela informalidade e em torno do Mercado Aberto, especificamente, bem como, acompanhamento do assunto em reportagens, jornais e revistas.

Verificou-se a necessidade de buscar informações que os questionários aplicados na primeira etapa não supriram. Assim, aplicaram-se mais quarenta (40) questionários aos feirantes do Mercado Aberto, todos respondidos. Dez (10) deles para os fiscais da Secretaria Municipal de Desenvolvimento Econômico (SEDEM) e da Secretaria de Fiscalização Urbana (SEFUR) que trabalham na fiscalização interna do Mercado Aberto, dos quais somente quatro foram respondidos, pois, no local e horário combinados, havia, disponíveis, apenas este número de trabalhadores; outros dez (10), para moradores situados ao redor do Mercado Aberto, com o retorno de quatro (4) formulários somente, pelo fato de muitos estarem trabalhando e outros indisponíveis ao atendimento; vinte (20) endereçados aos lojistas estabelecidos em torno do Mercado

\footnotetext{
${ }^{9}$ SEDEM - Órgão integrante da estrutura administrativa da Prefeitura de Goiânia, o qual tem por finalidade promover a execução da Política Municipal de Desenvolvimento Econômico da cidade.
} 
Aberto, dos quais quinze (15) questionários foram respondidos, em razão da falta de disponibilidade de tempo para a entrevista ${ }^{10}$.

\section{DISCUSSÃO \\ 3.1 Mercado Aberto: seu traçado}

Para uma maior compreensão da temática deste estudo, buscou-se vivenciar a realidade de Goiânia e acompanhar a construção do Mercado Aberto na Avenida Paranaíba, que tem funcionado desde abril de 2003, como mais um espaço reservado para funcionar como local de trabalho para os vendedores ambulantes. A este respeito, afirmou um feirante (F1), que já está no Mercado Aberto:

Nóis estava na Goiás e da Goiás tinha que sair, que da Goiás existia um tipo de despejo. Sabe como é que é. Era um despejo, era moradores que não queriam, era pessoas importantes que mora nessa Goiás, advogados e juízes e outros que não queriam, que sempre protestavam, saíam. Aí colocaram a... Arrumaram outra área, era sempre um despejo, tinha que sair. Brigaram por nada, brigaram para outro, brigaram por nada. Eu mesmo sou um dos que lutaram por essa área aqui. Optei por essa área, enfrentei uma grande resistência... (F1, 2004).

O Mercado Aberto surgiu da necessidade urbanística de revitalizar a Avenida Goiás, concomitantemente ao desejo de muitas pessoas em vê-la sem a atuação dos ambulantes. Sua escolha passou por processos de resistência por parte dos ambulantes que estavam na avenida. Os ambulantes não queriam deixar o ponto por haverem se acostumado a ele. Porém, apesar da resistência, foram organizadas comissões dos ambulantes, contando com a participação do Sindicato - SINCATEI - Sindicato dos Comerciantes Ambulantes e Trabalhadores da Economia Informal de Goiânia, com o objetivo de escolher um local mais adequado e em espaço fixo, conforme declarou F1:

Uns queriam uma área lá no Serra Dourada, outros lá na Praça do Trabalhador, outros falavam na antiga, lá na Pecuária, já ia ali. Tem disso, mas quase nenhuma não serve. Aí optamos por essa área aqui. Eu mesmo fui um dos que optei por essa área. Essa área aqui eu procurei um emprego um... um... no protocolo que retiramos, na época paguei vinte e cinco reais e poucos centavos para comprar o protocolo. Brigamos, brigamos, brigamos e saiu isso aqui. Essa aqui foi aprovada no governo do Nion Albernaz. Mas o Nion Albernaz aprovou, aprovou, mas não fizeram nada. É. Aí veio o Pedro Wilson. Fez a obra. Fez a obra. $(\mathrm{F} 1,2004)$

O Projeto Mercado Aberto atende a três eixos fundamentais do Plano de Governo: (a) inclusão social e universalização da cidadania; (b) construção de uma gestão pública democrática e popular permitindo a requalificação da cidade; e (c) auxiliar no desenvolvimento econômico e urbano de Goiânia. O projeto foi realizado na Administração Pedro Wilson, cujo mandato terminou em 2004. Esta idéia foi concretizada com a criação de um novo espaço em uma das áreas do Centro da capital, o que permitiu retirar os ambulantes de áreas que devem, aos olhos do planejamento

\footnotetext{
${ }^{10}$ A quantidade de questionários aplicados não obedeceu a uma amostra definida, mas optou-se por colher informações que possibilitassem um conteúdo sobre os enfoques deste estudo, por meio de questionários, relatos informais e gravados.
} 
urbano, serem protegidas e reservadas às funções para as quais foram originalmente criadas. Traz também algumas inovações como, por exemplo, servir de espaço para lazer, entretenimento e expressão cultural, após o recolhimento das bancas.

A área escolhida para abrigar o projeto é formada pelas ilhas da Avenida Paranaíba, entre as Ruas 68 e 74, espaço localizado à direita e à esquerda da Avenida Goiás, sendo um denominado de Canteiro 1 (entre a Rua 74 e Avenida Goiás) e o outro de Canteiro 2 (entre a Avenida Goiás e a Rua 68), com áreas de 4.593,69 m2 e 4.591,34 $\mathrm{m} 2$ respectivamente, num total de $9.185,03 \mathrm{~m} 2$ de área, desmembrados em seis áreas intituladas A, B, C, D E, F.

Para a implantação deste Projeto, foi feito o replantio de quarenta mudas de árvores de diversas espécies entre as Ruas 68 e 74, na região onde o Mercado Aberto funciona atualmente. A intenção desta proposta é proporcionar uma nova arborização, compatível com as características do ambiente urbano, compondo o projeto paisagístico da Avenida Paranaíba, com o objetivo de que esta via volte a ser verde.

O Mercado Aberto faz parte do projeto de implantação de mercados abertos de comércio ambulante para Goiânia ${ }^{11}$ que, de acordo com Santana, ${ }^{12}$ (2004), "ainda não tem nada definido para implantação de outros mercados em Goiânia, como em Campinas; isto porque é preciso primeiro reestruturar o Mercado Aberto da Avenida Paranaíba". A necessidade dessa reestruturação é fruto de demandas de muitos feirantes a respeito da estrutura do mercado que, conforme as reclamações, no início do funcionamento era mais organizado, cumprindo as normas internas, mas que, com o passar do tempo, foi tornando-se desorganizado: "Quando começou, melhorou um pouquinho... depois... veio a política, a política em cima, não... Não... Não... Não corrigiram o negócio direitinho, deixou bagunçado, ceis sabe que é feito política, eles deixam bagunçar as coisas. E aí bagunçou muito". (F1, 2004).

Como justificativa, o projeto surgiu para oportunizar aos ambulantes das Áreas do Centro de Goiânia condições que possibilitassem o seu crescimento econômico/social e o acesso ao mercado formal; viabilizar, através do gerenciamento e/ou Conselho Gestor em cada mercado aberto, o controle social dos empreendimentos; tratar o comércio ambulante como integrante de um conjunto de atividades econômicas importantes para a sobrevivência de significativo número de cidadãos; resolver os conflitos hoje existentes entre o comércio formal e os comerciantes ambulantes; tratar a questão dos trabalhadores ambulantes de forma inovadora, abrindo-lhes novas perspectivas de desenvolvimento pessoal e profissional, bem como envolver a sociedade civil através de suas representações políticas, do empresariado, dos diversos órgãos integrantes do Poder Público Municipal num projeto que materializasse os

11 Elaborado pela Secretaria Municipal de Desenvolvimento (Sedem), Secretaria de Planejamento (Seplan), Secretaria Municipal de Trânsito (SMT), Secretaria da Cultura (SeCult), Secretaria de Fiscalização (Sefur), e executado pela Sedem, Companhia de Pavimentação do Município de Goiânia (Dermu-Compav), Companhia de Obras (Comob), Comurg (Companhia de Urbanização de Goiânia), SMT, Cultura, Secretaria Municipal de Meio Ambiente (Semma) e Sefur; tem como programa: a requalificação do Centro Histórico de Goiânia; como modalidade: a geração de trabalho e renda; como ação: o reordenamento do comércio ambulante na região do Centro de Goiânia; como objetivo geral: a redefinição dos locais e condições operacionais do comércio ambulante nas áreas do Centro de Goiânia e específicos, a reorganizar as atividades com os trabalhadores ambulantes através da construção do Mercado Aberto da Paranaíba, da adequação da Rua 23 e Praça Espírito Santo, implementando programas de alfabetização, de desenvolvimento gerencial, de requalificação profissional para os trabalhadores, visando a dar solução aos conflitos entre ambulantes e comércio formal e a melhorar as condições de segurança e circulação dos pedestres no centro.

12 Dilma Pio de Santana. Assessora-chefe de Planejamento da Secretaria Municipal de Desenvolvimento Econômico - SEDEM. Entrevista concedida em 2004. 
compromissos do governo municipal com a construção da cidadania e não com um exercício desgastado de retórica política ${ }^{13}$.

Ao elaborar o Projeto Mercado Aberto ${ }^{14}$, o objetivo fundamental dos órgãos gestores era criar condições de trabalho diferenciadas para os vendedores ambulantes, resgatar a paisagem urbana, devolver os passeios públicos aos pedestres e levar à possível solução dos conflitos entre os setores formal e informal do comércio. Além desses quatro pontos prioritários do planejamento, o projeto visou também criar o Mercado Aberto como um local de animação do Centro da cidade, sendo, além de espaço para as atividades comerciais dos ambulantes, um local de lazer, de apresentações artísticas e culturais.

De acordo com o Memorial Descritivo Projeto Mercado Aberto, o Mercado Aberto está inserido na proposta de Estrutura Urbana do Plano Diretor de Goiânia, mais especificamente no item Instrumentos de Implementação. A função destes instrumentos é assegurar o cumprimento das Diretrizes Gerais e Setoriais da Política Urbana, bem como, no plano original da cidade, buscar incrementos, respeitando as características do comércio informal, incorporando uma infra-estrutura adequada à venda de mercadorias ao proporcionar conforto e dignidade dos usuários e feirantes na realização de suas necessidades básicas, tais como: alimentação, educação, vestuário, lazer etc.

O Mercado Aberto foi concebido, portanto, para funcionar como um espaço multiuso na cidade, trazendo para seu interior atores diferenciados, de diferentes classes sociais e/ou espaços de Goiânia, visitantes de outras cidades que vêm com a finalidade de fazer compras, curiosos, meninos de rua, moradores de rua, marginais etc., conferindo-lhe um caráter familiar. Ao saírem de suas casas ou de outros lugares e para o espaço do Mercado Aberto, seus freqüentadores criam uma espécie de identidade única entre si. Esse contexto demonstra a presença da pluralidade de atores urbanos que participam da conformação do espaço da cidade.

Verifica-se que todas as quintas-feiras, por exemplo, o entorno do Mercado Aberto, na Avenida Paranaíba, muda seu cenário de informalidade, ao sediar o encontro de cerca de trezentos motociclistas que se reúnem para beber e conversar. O encontro acaba atraindo outras pessoas, como curiosos que querem ver o que acontece entre eles, que desejam olhar de perto as motos exibidas e preparadas para o encontro - BMW, Kawasaki, Suzuki, Honda, Yamaha -, além de churrasqueiros e vendedores de bebidas. Todos juntos e juntas, os donos e donas das motocicletas vão ao local para mostrar a potência e a marca de suas motos, dando-lhes algumas marcas pessoais - acessórios para se tornarem mais atraentes em seus visuais.

Segundo a reportagem realizada pelo Diário da Manhã Revista, de 24 de agosto de 2004, o contador aposentado Moisés Santos, conhecido como Profeta, foi quem teve a idéia de reunir os motociclistas na Avenida Paranaíba. Além dos motociclistas, costumam encontrar-se nesse espaço grupos musicais e artísticos como capoeiristas, pessoas que querem apenas comer ou tomar algo nos lanches espalhados no local, encontrar amigos ou mesmo participar isoladamente. Através das abordagens realizadas com as pessoas que passavam pelo Mercado Aberto e aquelas que estavam por lá após a saída dos feirantes, o espaço fica disponível para encontros de pessoas e grupos que queiram expressar algo coletivamente ou simplesmente encontrar-se com os amigos.

\footnotetext{
${ }^{13}$ Disponível em: http://www.goiania.go.gov.br

${ }^{14} \mathrm{O}$ projeto completa-se com a expansão para a Rua 23 e para a Praça Espírito Santo, ao lado do Parthenon Center, para aqueles que não conseguiram vagas na Avenida Paranaíba.
} 
Este projeto que, até abril de 2003, abrigava 1 mil e 390 feirantes (número que em 2004 saltou para mais de 2.000 bancas) no Mercado Aberto da Avenida Paranaíba, e 80 no Projeto de Extensão da Praça Prof. Felicíssimo do Espírito Santo, totalizando 1 mil e 470 feirantes, atende aos seguintes programas: Programa de Redefinição de Uso de Áreas Públicas destinadas a equipamentos comunitários; Programa de Dinamização de Pólos de Desenvolvimento Regional e Subprogramas de Definição UrbanísticoEspacial, que consistem na definição do desenho urbano das áreas componentes de Pólos de Desenvolvimento Regional; Programa de Dotação Urbana, que se baseia no levantamento das necessidades de suporte aos equipamentos urbanos e comunitários próprios a cada intervenção, bem como na programação dos investimentos necessários e incentivo à transferência de atividades econômicas visando a estabelecer estímulos que possam provocar a transferência de determinadas atividades incompatíveis com sua atual localização, atraindo-as aos Pólos de Desenvolvimento propostos, segundo sua natureza. Segundo a SEDEM, com base em dados da Câmara de Dirigentes Lojistas (CDL), já houve um aumento de $20 \%$ nos negócios do comércio formal a partir da realização deste projeto.

Foi estabelecido um Termo de Compromisso e Ajustamento de Conduta junto ao Ministério Público de Goiás, para melhor garantir a ordenação e funcionamento do Mercado Aberto. Assim, todos que pretendiam uma vaga no projeto deviam preencher os requisitos, isto é, não possuir outra concessão pública nem algum impedimento jurídico. A emissão de licenças para este tipo de comércio é fornecida pela SEDEM, de acordo com seu regimento interno aprovado pelo Decreto 1.229/99. De acordo com o artigo $5^{\circ}$, parágrafo $2^{\circ}$, a SEDEM tem competência para promover a execução da Política Municipal de Desenvolvimento Econômico.

O processo de seleção dos feirantes seguiu a determinação da Comissão Administrativa de Feiras Livres e Especiais - CAFLE - criada pela resolução n. ${ }^{\circ}$ 00772002, atendendo às exigências do Decreto n. ${ }^{\circ}$ 2.834, de 30 de julho de 2001. Quatrocentos e um ambulantes foram priorizados por já possuírem cadastro e por estarem trabalhando, perfazendo cerca de $48 \%$ das vagas. O restante das vagas foi destinado aos ambulantes que atuavam no Centro Histórico de Goiânia. Deste montante, $20 \%$ foram reservadas para os ambulantes jovens, $12 \%$ para os ambulantes com idade acima de 45 anos, 12\% para as mulheres ambulantes chefes de família, 5\% para os portadores de necessidades especiais e 3\% para ambulantes egressos do sistema penitenciário. As vagas foram sorteadas utilizando-se o método aleatório.

O Mercado Aberto enquadra-se nas chamadas Feiras Especiais aprovadas pelo Decreto n. ${ }^{\circ}$ 2.834, de 30-07-2001, sancionado pelo então prefeito Pedro Wilson Guimarães. Segundo este decreto, as feiras especiais serão implantadas, orientadas e supervisionadas pela SEDEM e fiscalizadas pela Secretária Municipal de Fiscalização e destinam-se à comercialização de produtos alimentícios preparados e semipreparados, bem como artigos artesanais manufaturados e semimanufaturados, floricultura e produtos naturais.

Amparado por este decreto, o Mercado Aberto possui normas que disciplinam seu funcionamento, entre as quais estão aquelas referentes à montagem e desmontagem das bancas, atividade que fica a critério do feirante ${ }^{15}$, desde que obedeça ao horário estabelecido, que não poderá ultrapassar duas horas no início, nem uma hora no término das atividades das feiras.

\footnotetext{
${ }^{15}$ Os ambulantes que trabalhavam nos espaços públicos do Centro de Goiânia e que foram transferidos para o Mercado Aberto são chamados de feirantes.
} 
Pelas ações dos vendedores ambulantes, verificou-se, no decorrer desta pesquisa, que o espaço delimitado como campo exploratório abre-se como um leque de onde saem outras ações e outros participantes da cidade.

O Mercado Aberto pode ser justificado pelo que Attílio Correia Lima apresentou em seu plano para Goiânia ${ }^{16}$, no que se refere ao funcionamento da Avenida Paranaíba, de acordo com o qual cabia a ela a função de abrigar feiras e todos os divertimentos ou comércios periódicos.

\subsection{Mercado Aberto: seu funcionamento e normatizações.}

O Mercado Aberto é composto por bancas que comercializam produtos variados como sapatos, sandálias, relógios, bijuterias, roupas infantis, juvenis e adultas, alimentos, CDs e outros. Em seu espaço, podem ser encontrados sanitários para ambos os sexos e para portadores de deficiências, serviço de Som Onda Livre, praça de alimentação, provadores de roupa, guarita de fretistas, guaritas para policiais, espaço para administração e copas, funcionando, de segunda a sexta-feira, das 9 às $19 \mathrm{~h}$, e aos sábados e feriados e/ou datas comemorativas, das 9 às 18 horas.

Verifica-se no Mercado Aberto aproximadamente 2.100 bancas de produtos, 20 lanchonetes e 12 banheiros, inseridos em duas quadras, cada uma é constituída por áreas nomeadas A, B, C, D, E e F. Possui um sistema de comunicação denominado Rádio Onda Livre, que abriga sete radialistas e dois jornalistas, a maioria dos quais é de estagiários que estuda na Universidade Federal de Goiás, conforme afirmou um fiscal interno do Mercado Aberto, lotado na Secretaria de Fiscalização.

O serviço de som do Mercado Aberto ${ }^{17}$ é composto de duas subestações, ficando localizada uma em cada canteiro (quadra) do Mercado Aberto. A Rádio, que é dirigida e gerenciada pela Prefeitura de Goiânia, possui um responsável pela programação local e pela utilização dos serviços de utilidade pública e gratuita pelos funcionários e usuários do Mercado. Além de toda a estrutura para seu funcionamento, o Mercado Aberto funciona como um espaço de conflitos, onde diversas linguagens se comunicam,

\footnotetext{
16 “A larga faixa formada pela Av. Paranaíba e que separa a zona comercial da zona industrial, ficará reservada para feiras e todos os divertimentos ou comércios periódicos.” (Relatório Técnico. In: Memorial Descritivo. Projeto Mercado Aberto, Avenida Paranaíba. Goiânia. Prefeitura de Goiânia. Secretaria de Planejamento Municipal, SEPLAM, 2001).

17 O serviço de som do Mercado Aberto denominado Onda Livre é mantido pela Secretaria de Comunicação da Prefeitura de Goiânia, por meio do Núcleo de Articulação com a Sociedade NUARTS/SECOM. De segunda a sábado, a Onda Livre apresenta informações, música, entretenimento e prestação de serviços. Resumidamente, a Rádio funciona da seguinte forma: de segunda a sábado, às $8 \mathrm{~h}$ $30 \mathrm{~min}$, a rádio apresenta o programa Começando o Dia, que dirige uma reflexão para iniciar o dia a todos que se encontram no Mercado Aberto; às $13 \mathrm{~h}$ das terças-feiras vai ao ar o programa Minha História, um quadro aberto para que todos que fazem o Mercado Aberto contem suas histórias, suas lutas e esperanças; às $13 \mathrm{~h}$ das segundas, quartas e sextas-feiras e às $9 \mathrm{~h}$ dos sábados é apresentado o programa Na sua Opinião, um bate-papo ao vivo sobre temas locais, nacionais e internacionais; às $13 \mathrm{~h}$ das quintasfeiras, no quadro Histórias que a Cidade Conta, são convidadas pessoas que fazem a história de um lugar para dar seus depoimentos; às 10 h e às 16 h 30min, de segunda a sexta-feira, vai ao ar o quadro Geração Esportiva, que é um espaço para a equipe de "doutores da bola" da Rádio Universitária transmitir informações sobre o esporte amador e profissional de Goiás, do Brasil e do mundo; de segunda a sextafeira ás $9 \mathrm{~h}$ e às 15 h, e no sábado às 10 h é apresentado o programa Cerrado em Canto, uma produção musical do cerrado com a veiculação de entrevistas de músicos e artistas; de segunda a sexta-feira ás $11 \mathrm{~h}$ e às $14 \mathrm{~h}$, e no sábado as $11 \mathrm{~h}$ é apresentado o programa Trêis mió Di Bão, um quadro onde a seleção musical é feita pelos próprios ouvintes; de segunda a sábado, ao final de cada programa, vai ao ar Mercado em Rede, um informativo jornalístico de interesse publico; e de segunda a sexta às $16 \mathrm{~h}$, e no sábado às 11 h 15 min, é oferecido Goiânia no ar, um programa jornalístico com noticias locais, do Brasil e do mundo.
} 
identificando-se entre elas a linguagem do feirante, a da fiscalização, do usuário e dos órgãos responsáveis pelo projeto. Nessa comunicação fica visível a divergência de interesses.

As bancas de mercadorias que são encontradas funcionando fora do horário permitido (das 9 às 19 horas) são compulsoriamente apreendidas pela fiscalização, sujeitando-se $\mathrm{o}$ infrator às penalidades legais ${ }^{18}$. A energia elétrica consumida pela banca é de responsabilidade de cada feirante, na proporcionalidade de seu consumo, conforme critério definido pela entidade responsável pela concessão de energia.

$\mathrm{O}$ feirante interessado em regularizar-se junto à Prefeitura deve dirigir-se à SEDEM, o órgão responsável pelo cadastramento, e preencher uma ficha socioeconômica, além de apresentar documentos tais como: cópia da Carteira de Identidade, cópia do CPF, comprovante de que reside no município de Goiânia, ou no seu entorno, há no mínimo dois anos, comprovante de domicilio eleitoral em Goiânia ou no seu entorno, e certidões criminais negativas, expedidas pela Justiça Estadual e Federal.

O descumprimento de qualquer item previsto no decreto que normatiza o funcionamento do mercado (Decreto n. ${ }^{\circ}$ 2.834) acarretará penalidades, tais como advertência por escrito, suspensão das autorizações para atividades feirantes pelo período de 15 dias, apreensão das mercadorias e/ou da banca, cancelamento da autorização para exercer atividade feirante, a critério do poder público, respeitando-se o direito ao contraditório e a ampla defesa.

Na concepção dos órgãos responsáveis pela organização da cidade ${ }^{19}$, os projetos urbanísticos trazem implícita ou explicitamente a idéia de que os camelôs conferem uma mancha "indesejada" aos espaços públicos, o que deixaria esses lugares com traços de desordem, bagunça, sujeira. Para devolver à cidade o ar de ordem, limpeza e segurança, o Projeto Mercado Aberto constituiu-se numa saída mais funcional e racional, ao fixar a normatização dessa prática, oferecendo aos vendedores ambulantes o título de feirantes, com deveres e direitos trabalhistas. ${ }^{20}$

\subsection{Tributos ao Mercado Aberto: sua realidade cotidiana.}

Por meio de entrevistas realizadas com os feirantes do Mercado Aberto, foi possível compreender o grau de satisfação com o projeto, bem como a validade de alguns pontos centrais de sua concepção. Perguntando-lhes sobre o que achavam da construção do Mercado na Avenida Paranaíba, várias opiniões foram levantadas:

\footnotetext{
${ }^{18}$ Ver em "Normas para o funcionamento de Feiras Livres e Especiais no Município de Goiânia".

${ }^{19}$ É importante perceber que, em outras cidades brasileiras, existe a preocupação em ordenar as práticas dos ambulantes na ótica dos órgãos municipais. Em Recife, por exemplo, existe o Calçadão dos Mascates, projeto de arquitetura de autoria de Ronaldo L' Amour, onde à noite todas as atividades fecham suas portas e o local se transforma em espaço de lazer popular. Em Curitiba, a prefeitura local fixou um quantitativo de 500 camelôs espalhados pelo Centro Urbanístico, não permitindo que eles se estabeleçam em locais fixos.

${ }^{20}$ Essa proposta foi implantada durante a administração do prefeito Pedro Wilson Guimarães, que assumiu a Prefeitura de Goiânia para o período 2001-2004, com a intenção de realizar um governo democrático, comprometido com a construção de um governo unido, fundado num modelo de gestão democrática e participativa, com capacidade para fazer a inversão de prioridades e ampliar a participação popular. Sua estratégia de planejamento tem como referência os pressupostos do Planejamento Estratégico Democrático -PED, desenvolvido por Ademar Sato e sua equipe.
} 


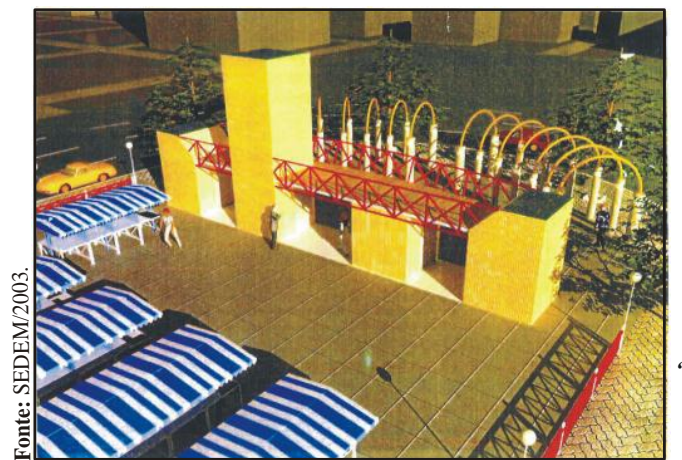

“Ruim, a Goiás era melhor”.

"Foi bom por um lado, mas falta muita coisa a ser feita".

"Não ficou bom, prejudicou muita gente”.

"Ficou mal feita".

"Muito bom".

"Não é das melhores, prejudicou muita gente”.

"Pôr um lado piorou, por outro melhorou".

“É bom, porém, deveria ter cobertura e acabar com a chamada, uma espécie de ponto".

"Não foi um projeto ruim, só que precisa de mais clientes, propaganda".

$$
\begin{aligned}
& \text { “Legal”. } \\
& \text { "Não gostei". }
\end{aligned}
$$

Para a maioria dos feirantes, a construção do Mercado Aberto significou, num primeiro momento, um projeto capaz de melhorar suas condições de trabalho mas que, quando foi aplicado, deixou muito a desejar, especialmente em virtude da falta de consumidores. Os feirantes atribuem a escassez de consumidores ao deslocamento das bancas para um local afastado dos pontos de ônibus, onde há pouca circulação de possíveis compradores.

Ao conversar com os feirantes, percebe-se haver o consenso entre eles de que a infra-estrutura colocada à disposição do Mercado Aberto é insuficiente. Como exemplo, apresentam a ausência de limpeza nos banheiros e nos próprios corredores onde, segundo eles, o mau cheiro às vezes é insuportável. Outra dificuldade apresentada pelos feirantes refere-se à organização interior das bancas pois, segundo eles, algumas ficam quase escondidas, o que dificulta que sejam vistas pelas pessoas que por lá circulam.

Quando os feirantes afirmam que a Avenida Goiás era melhor para a prática de sua profissão de ambulante, usam duas justificativas principais. Em primeiro lugar, afirmam preferir a Avenida Goiás porque neste local adquirem maior visibilidade em razão de esta avenida ser uma via pública localizada em um canteiro central que divide duas vias movimentadas, além de se situar em meio ao comércio formal onde transitava um número maior de pessoas que já estavam acostumadas a realizar compras naquele local. Em segundo lugar, porque quando estavam na Avenida Goiás não eram obrigados a se submeter às normas de funcionamento do Mercado Aberto, especialmente no que se refere ao seu horário de funcionamento. É claro que quando estavam na Avenida Goiás, os ambulantes obedeciam a certas regularidades para trabalhar como, por exemplo, a obrigação de terem um cadastro e serem obrigados a responder chamadas realizadas pelos fiscais. Mas apesar disso, as normas não eram muito rígidas no que se referia aos horários de entrada e saída como acontece no Mercado Aberto.

$\mathrm{Na}$ fala dos feirantes, o Mercado Aberto possui aspectos positivos e aspectos negativos. É positivo o fato de possuírem um espaço onde podem trabalhar legalmente, onde todos são obrigados a cumprir as normas internas, onde existe alguma infra- 
estrutura como banheiros e onde existe segurança dada pela Polícia Militar e pela fiscalização interna. Todos esses pontos considerados positivos pelos feirantes inexistiam na Avenida Goiás, o que causava muitos transtornos. Entre os aspectos negativos mencionados, podem ser citados a falta de cobertura mais ampla para as bancas de modo a proteger feirantes e mercadorias dos rigores do sol e das chuvas fortes. A esse respeito, afirmou um feirante (F2):

(...) a obra aqui ficou boa, ficou boa. Só falta a cobertura. É uma coisa absurda isso aqui porque, quando chove, a gente fica sem a mínima condição de trabalhar porque...(...) molha de mais em cima, empoça água demais, molha demais. E quando vem calor, também é insuportável o calor aqui. Tem outras lonas ali. Essa lona nós colocamos para tampar esses buracos, uai, porque essas bancas não têm beiral; olha lá como é que é: ela não tem beiral. Essa lona a gente tem que colocar...essas azuis foram nós que colocamos, cada qual compra isso aí e coloca. Eu mesmo coloco essa lona, que ela serve pra quatro barracas. Eu, eu coloco que serve pra quatro companheiros. Eu mesmo chego e coloco, e ...ela não veda água mais não. Ele, eles, eles falaram que no começo essa lona tinha uma proteção solar, que não sei o que, que não esquentava. Mas ela esquenta absurdo, chega pega fogo. Olha, pessoas, pessoas novo aqui dentro passa mal; agora você imagina pessoas da minha idade... (F2, 2004).

Esta deficiência justifica a fala de um dos feirantes que se referiu ao Mercado Aberto como uma construção mal feita, com pouca divulgação do projeto para a população de Goiânia, cujas normas os fazem sentir presos e limitados demais em suas ações, como chegar e sair do Mercado Aberto a hora que escolherem e estarem o tempo todo submetidos a ordens de proibições para venda de seus produtos:

Olhe só, veja, não posso ir para o corredor do Mercado, senão, se o fiscal vê, briga; e a minha banca fica escondida como você vê; ninguém vê meus produto; vendo meia, mais todo mundo que passa aqui não vê, olha mais pra banca da ponta, as do fundo quase ninguém olha não. E aí quem fica no prejuízo? Eu, minha filha; a Prefeitura tá ficando rica. (F3, 2004).

O discurso acima revela uma rejeição ao Projeto Mercado Aberto. Porém, o mesmo feirante que diz não estar gostando, concorda com as falas que apresentam o lado bom do projeto. Esse feirante, que aparenta ter uns cinqüenta anos de idade, demonstra estar desgostoso por encontrar-se num local do Mercado Aberto que para ele é ruim, embora aprove estar num local fixo para suas vendas, um lugar dotado de banheiros, segurança e espaço para guardar seus produtos.

De acordo com o discurso dos usuários, os vendedores/feirantes aceitaram ser transferidos para o Mercado Aberto. Mas ao se depararem com os problemas internos apontados acima, acabam por ter que trabalhar em outros locais como a Feira Hippie, Feiras Especiais nos bairros, Avenida 24 de Outubro etc., colocando outra pessoa para tomar conta de suas bancas, o que é proibido pela fiscalização interna.

Essa situação é complexa. Sabemos que muitos desses feirantes compram espaços em diversas feiras e colocam parentes, amigos e pessoas conhecidas para trabalhar. Assim, um feirante que é dono de sua banca, ou seja, que paga para ficar no ponto do Mercado Aberto, acaba colocando outra pessoa em seu lugar, enquanto vai tomar conta de outro ponto em outro espaço da cidade. Apresentam como justificativa 
para a múltipla posse de pontos o fato de que uma só banca é insuficiente para prover a subsistência sua e de sua família. Diante disso, percebe-se a ocorrência de um processo de mercantilização dos espaços em Goiânia, onde o espaço público realmente tornou-se espaço privado, sujeito a aluguel pelos donos das bancas.

Por sua vez, os usuários-consumidores aprovam a construção do Mercado Aberto por considerá-lo útil e necessário à população de baixa renda em razão de ser mais uma opção no comércio varejista de Goiânia, além de ser responsável pela geração de novos empregos. A falta de liberdade e excessivo controle de que os ambulantes tanto reclamaram são vistos pelos consumidores como algo bom, ao dizerem que Mercado Aberto para eles significa organização.

A dinâmica desenvolvida no Mercado Aberto pode ser vista como o embate entre o desejo dos feirantes de realizarem sua atividade comercial do jeito que quiserem e a vontade dos consumidores e daqueles que estão fora dessa atividade informal de vêlos organizados na cidade como forma de não prejudicar o cotidiano da cidade.

As pessoas que compram mercadorias no Mercado Aberto vêem-no como um espaço de compras público, com produtos baratos e variados, alguns de boa qualidade e outros não, onde sejam bem atendidos. Outros percebem o mercado como uma organização interna levada a bom termo em razão da fiscalização que existe em seu interior, configurando-se numa alternativa de compra para todos, mais especialmente para as pessoas de baixa renda.

\subsection{Caminhando contra o vento sem lenço sem documento eu vou... Mercado Aberto, um espaço de conflitos.}

Durante a criação do Projeto Mercado Aberto, surgiram muitas controvérsias. Entre estas, uma das mais importantes foi a dificuldade em enquadrar todos os ambulantes das Áreas do Centro de Goiânia, as Avenidas Anhangüera, Goiás e Paranaíba, Tocantins, Araguaia, Ruas 2, 3, 4, 6, 7, 8, 9 e 30 num espaço único ao longo da Avenida Paranaíba e, logo, de manter os ambulantes selecionados no novo espaço. Reportagens publicadas em jornais locais revelaram essa problemática, ao registrar que um mês após a construção e funcionamento do Mercado Aberto os ambulantes voltaram para os mesmos locais do Centro da cidade, mesmo em feriados.

Além da dificuldade na emancipação do projeto, verifica-se que esse espaço se choca com a identidade dos ambulantes, que agem de acordo com sua realidade de ambulante, como alguém livre que não tem ponto fixo para trabalhar. Ocupando os locais do Centro, mesmo nos feriados da cidade, os ambulantes garantem as vendas dos seus produtos orientando suas ações pela lógica do trabalho e da sobrevivência. Compreende-se, assim, que a dinâmica do ambulante desenvolve-se pela guerra dos lugares $^{21}$, já que eles lutam para vender suas mercadorias onde há circulação de pessoas.

Após a transferência da Avenida Goiás, repercutiu as opiniões e os sentimentos positivos e negativos quanto a participação dos feirantes na experiência inovadora do Mercado Aberto. Indagados sobre o local que consideravam mais adequado para trabalharem, se na Avenida Goiás ou no Mercado Aberto, a maioria opta pela primeira e apresenta como razão fundamental da escolha a inexistência de obrigatoriedade de sujeição às normas exigidas pelo mercado, como a submissão à fiscalização urbana constante e intensiva e a proibição de terem mais de um ponto de venda. Dessa perspectiva, o que os feirantes desse local revelam é o desejo de serem ambulantes de fato, não tendo que se aproximar de outros comerciantes, podendo vender seus produtos

\footnotetext{
${ }^{21}$ O conceito de "guerra dos lugares" foi retirado da obra de Arantes, Antônio A. Paisagens Paulistanas. Transformações do Espaço Público. São Paulo: Imprensa Oficial. 2000. P. 105.
} 
pela cidade sem se preocuparem com a fiscalização: "Já que sou ambulante, quero ser ambulante, que é isso: não ter ponto fixo, vender aonde quiser, não ter horário" (F4, 2004).

O Mercado Aberto foi criado a partir de um traçado arquitetônico que revela um espaço cercado de grades pequenas que delimitam o território dos feirantes, adequandose ao tamanho das bancas, dimensão previamente fixada pela prefeitura. Pode-se perceber o espaço do mercado como uma mescla de público e privado, ao ser local de trabalho por excelência dos feirantes transferidos, mas também espaço de compra para qualquer pessoa da cidade a partir de uma legislação que normatiza o comportamento dos feirantes, vigiando-os constantemente através da fiscalização e punindo-os quando necessário.

\section{CONSIDERAÇÕES FINAIS}

\subsection{Mercado Aberto: regras que foram feitas para serem quebradas.}

Observa-se uma visão ambígua nos depoimentos dos feirantes. De um lado, muitos ambulantes abordados consideram o Mercado Aberto como suas próprias casas, já que passam a maior parte de suas vidas dentro dele. De outro, consideram-no como algo muito ruim, representado pela sujeira e mau cheiro, refletindo as más condições de trabalho com que convivem diariamente. Esses sentimentos foram representados por um desenho feito por um feirante (F5) do Mercado Aberto, que procurou expressar o sentimento de muitos dos seus colegas feirantes, revelando num primeiro quadro do desenho que o local deveria ter mais infra-estrutura, ser mais limpo, e, em outro, a consideração pelo Mercado que, além de ser local de trabalho, torna-se para muitos local de intimidade, familiar - uma casa - pelo fato de estarem ali a maior parte do dia

Mesmo convivendo com as ambigüidades, controle, fiscalização, ordenamento, no cotidiano do Mercado Aberto, na prática da cidade, novas sociabilidades são forjadas e reforjadas nesse espaço concreto. Percorrendo as fileiras das barracas, percebe-se que ele é reconfigurado pelas linguagens, comportamentos e jeitos dos feirantes, apesar da disposição e o arranjo feitos pelos órgãos responsáveis, que ordenam a cor, os locais, a chegada e saída no seu interior.

As normas existem para ser cumpridas, mas à medida que a fiscalização se distancia por algum tempo, o feirante atua no espaço buscando contrariar as regras existentes. Como isto acontece? Prestando muita atenção, percebe-se que muitos feirantes, principalmente aqueles mais ousados, deixam suas bancas e saem para mostrar seus produtos em outras quadras, nos corredores, indo ao encontro das pessoas que por ali passam, ou colocando outra pessoa para vender seus produtos, prática que evidencia a resistência às normas a que são submetidos.

O Mercado Aberto constitui-se num plano que atua como forma de organizar os espaços históricos, centrais e públicos de Goiânia. Assim, acredita-se que o mercado é um processo de interação social desenvolvido na cidade ao ser construído num local público - Avenida Paranaíba -, propiciando o encontro dos trabalhadores da informalidade com outras pessoas da cidade, isto é, moradores, lojistas e todos aqueles que vivem e trabalham em Goiânia.

\section{REFERÊNCIAS}

FONTANEZI, Janete Romano. No centro da capital da primavera: Goiânia - corpo e alma (1930 - 2000). (Trabalho apresentado no Seminário como exigência parcial do Mestrado em História da Universidade Federal de Goiás, 2002 - 2004). Goiânia, 2003. FONTANEZI, Janete Romano. No centro de uma capital planejada: Goiânia - corpo (forma) e alma (memória) (1930 - 1970). (Parte da dissertação para qualificação como 
exigência parcial do Mestrado em História da Universidade Federal de Goiás, 2002 2004). Goiânia, 2004.

ARANTES, Antônio A. Paisagens Paulistanas. Transformações do Espaço Público. São Paulo: Imprensa Oficial, 2000.

ARANTES, Otília. all. A cidade do pensamento único. Desmanchando consensos. Petrópolis: Vozes, 2000.

THIOLLENT, Michel. A Crítica metodológica, investigação social e enquete operária. São Paulo: Pólis, 1980.

HAGUETTE, Teresa Maria Frota. Metodologias qualitativas na sociologia. Petrópolis: Vozes, 1992.

\section{ENTREVISTADOS (AS)}

FEIRANTES. Mercado aberto. Goiânia. Entrevistas concedidas em 2003 e 2004.

FISCAIS. Fiscalização urbana. Goiânia (SEFUR). Entrevistas concedidas em 2003 e 2004.

FUNCIONÁRIOS. Secretaria de Planejamento Municipal (SEPLAM). Entrevistas concedidas em 2003.

FUNCIONÁRIOS. Secretaria Municipal de Desenvolvimento Econômico (SEDEM). Entrevistas concedidas em 2003 e 2004.

LOJISTAS. Áreas do centro em torno do Mercado Aberto. Goiânia. Entrevistas concedidas em 2004.

MORADORES. Áreas do centro em torno do Mercado Aberto. Goiânia. Entrevistas concedidas em 2004.

SANTANA, Dilma Pio de. Assessora-chefe de Planejamento da Secretaria Municipal de Desenvolvimento Econômico - SEDEM. Entrevista concedida em 2004.

SUPERINTENDENTES. Secretaria Municipal de Desenvolvimento Econômico (SEDEM). Entrevistas concedidas em 2003 e 2004.

Vendedores ambulantes. Setor Campinas. Goiânia. Entrevistas concedidas em 2003 e 2004.

\section{REVISTAS}

Revista. Pólis. Goiânia, 1996. n. 23.

Revista. O Lojista. 2003.

\section{ÓRGÃOS}

Centro de Documentação de $O$ Popular (CDOC).

Instituto de Geografia e Estatística (IBGE). Goiânia.

Relação Anual de Informações Sociais do Ministério do Trabalho e Emprego.

Secretaria de Planejamento Municipal (SEPLAM). Goiânia.

Secretaria Municipal de Desenvolvimento Econômico (SEDEM). Goiânia, 2001.

Sindicato dos Comerciantes Ambulantes e Trabalhadores da Economia Informal de Goiânia (SINCATEI).

\section{JORNAIS}

O Popular. Presidente da Câmara de Dirigentes Lojistas de Goiânia - CDL. Goiânia. 22 de mai. 2003.

Diário da Manhã. Meu Bairro. Goiânia. 6 jun. 2004. 


\section{ENDEREÇOS ELETRÔNICOS}

www.goiania.go.gov.br

\section{DOCUMENTOS}

Memorial Descritivo Projeto Mercado Aberto. Avenida Paranaíba. Uma alternativa de relocação para bancas de comércio informal instaladas no canteiro central da Avenida Goiás - Setor Central. Prefeitura de Goiânia. Secretaria de Planejamento Municipal. Goiânia, 2001.

Normas para o funcionamento de Feiras Livres e Especiais no Município de Goiânia. Secretaria Municipal de Desenvolvimento Econômico, 2001.

Plano de Desenvolvimento Integrado de Goiânia (PIDG). Goiânia. vol. I.(2000). Regulamento de Saúde Publica, de 1931. 